\title{
Announcing the call for the Issue Focus on the 2nd Costa Rican Biophysics Symposium—virtual meeting, March 2021
}

\author{
Christopher Solís ${ }^{1}$ (D) - Gustavo Chaves ${ }^{2}$ (i) • José Ángel Rodriguez-Corrales ${ }^{3}$ (i) \\ Accepted: 25 June 2021 / Published online: 6 July 2021 \\ (C) International Union for Pure and Applied Biophysics (IUPAB) and Springer-Verlag GmbH Germany, part of Springer Nature 2021
}

\begin{abstract}
This Commentary is a call for submissions for the upcoming Issue Focus that will highlight some of the scientific topics discussed during the $2^{\text {nd }}$ Costa Rica Biophysics Symposium.
\end{abstract}

The Second Costa Rican Biophysics Symposium ${ }^{1}$ was organized on March $11^{\text {th }}$ and March $12^{\text {th }}$ of 2021. The first edition of this symposium was organized in 2019 at the National Academy of Sciences in Costa Rica (Solís et al. 2020). Due to the success of this event, the organizers decided to pursue a second edition of this scientific meeting. However, the global emergency of COVID-19 forced to keep social distancing as part of the sanitary measures and therefore, the second edition was held virtually. Nevertheless, the event was a great success as measured by the number of registrations near to 130 , the quality of the presentations of the 15 speakers from 5 different countries (Costa Rica, Switzerland, USA, France, and Germany), and the level of participation during the $\mathrm{Q} \& \mathrm{~A}$ sessions of each talk. As the highlight of the symposium, we had the pleasure to host Dr. Francisco Bezanilla as the keynote speaker and who highlighted some of his recent work on noncanonical mechanisms of voltage sensor domain coupling to pore domains in voltage-gated potassium channels (Carvalhode-Souza and Bezanilla 2019).

In commemoration of the $2^{\text {nd }}$ Costa Rica Biophysics Symposium, Biophysical Reviews will publish an Issue Focus in 2022 highlighting some of the scientific topics discussed during the event. Review articles from speakers

${ }^{1}$ https://crbiophysics.wordpress.com/programa/

Christopher Solís

csolisoc@uic.edu

1 Department of Physiology and Biophysics, College of Medicine, The University of Illinois at Chicago, Chicago, Illinois, USA

2 Institute of Physiology, Pathophysiology and Biophysics, Klinikum Nürnberg Medical School - PMU Nürnberg, Nuremberg, Bavaria, Germany and attendees who were part of the event are solicited. The format for the review articles is similar to those submitted for the special issue of the $20^{\text {th }}$ International Congress of the International Union of Pure and Applied Biophysics (IUPAB) (Itri et al. 2021). The Special Issue for the $20^{\text {th }}$ IUPAB International Congress will be prepared and edited by the current authors (Christopher Solís, Gustavo Chaves, and José Ángel Rodriguez-Corrales).

\section{Submission deadline}

Review articles are requested to be submitted prior to December 1st of 2021 with online publication scheduled for Issue 2 of 2022. When submitting your article, please choose the correct Special Issue/Meeting Focus assignment.

\section{Submission format}

Biophysical Reviews publishes two types of review formats. A short review (3000-4000 words, 3 figures) or a long review (10,000 words, 10 figures).

Journal homepage

http://www.springer.com/journal/12551

Online submission

https:/www.editorialmanager.com/brev/

Journal social media

Twitter ${ }^{\mathrm{TM}}$ : @ BiophysicalRev1

YouTube ${ }^{\mathrm{TM}}$ : https://www.youtube.com/channel/UCzG 5MWmnrB2UBibtxs2DuA 


\section{References}

Carvalho-de-Souza JL, Bezanilla F (2019) Noncanonical mechanism of voltage sensor coupling to pore revealed by tandem dimers of Shaker. Nat Commun. 10(1):3584. https://doi.org/10.1038/s41467019-11545-7

Itri R, Baptista MS, Garratt R, da Costa Filho AJ (2021) Announcing the call for the Special Issue on the 20th International Congress of the International Union of Pure and Applied Biophysics (IUPAB)- virtual meeting, October 2021. Biophys Rev. 13(2):1-2. https:// doi.org/10.1007/s12551-021-00796-8

Solís C, Rodríguez-Corrales JA, Alvarado FJ (2020) Lessons learned from organizing a biophysics symposium in a developing country. The Biophysicist 1(2):2. https://doi.org/10.35459/tbp.2019.000144

Publisher's note Springer Nature remains neutral with regard to jurisdictional claims in published maps and institutional affiliations. 